\title{
THE USE OF NONSTEROIDAL ANTI-INFLAMMATORY DRUGS AND THE OCCURRENCE OF GASTRIC LESIONS AMONG PATIENTS UNDERGOING UPPER ENDOSCOPY IN A UNIVERSITY HOSPITAL IN BRAZIL
}

\author{
Andreia Queiroz Ribeiro, Gil Sevalho, Cibele Comini César
}

\begin{abstract}
Ribeiro AQ, Sevalho G, César C. The use of nonsteroidal anti-inflammatory drugs and the occurrence of gastric lesions among patients undergoing upper endoscopy in a university hospital in Brazil. CLINICS. 2006;61(5): 409-16.
\end{abstract}

BACKGROUND: Nonsteroidal anti-inflammatory drugs are widely used in Brazil in spite of the known risks associated with their use, but investigation of their side effects conducted in this country has been far from sufficient. This study investigates the use of NSAIDs among patients undergoing upper endoscopy in the Hospital das Clínicas of the Federal University of Minas Gerais and the association of this use with the endoscopic diagnosis of gastric erosions, gastric erosions with hematin pigmentation, and gastric ulcer.

METHODS: The cross-sectional methodological approach was used; 533 patients aged 17 or older were interviewed, between June and December, 2000. Data were submitted to bivariate and multivariate analyses.

RESULTS: More than two thirds of the interviewed population reported the use of nonsteroidal anti-inflammatory drugs in a period of 1 month before the upper endoscopy. The most used nonsteroidal anti-inflammatory drugs were acetylsalicylic acid and diclofenac. An association was clearly shown between the use of these drugs and the occurrence of the studied lesions, with the latter attaining significance. There was also a significant association between nonsteroidal anti-inflammatory drugs use for a period greater than 15 days and the occurrence of the gastric lesions, with a higher odds ratio than for the other comparisons.

CONCLUSIONS: The results suggest that nonsteroidal anti-inflammatory drugs have a significant association with the occurrence of the gastric lesions and point to the need of further study of this issue in Brazil.

KEYWORDS: Pharmacoepidemiology. Nonsteroidal anti-inflammatory drugs. Upper endoscopy. Adverse drug reaction.

\section{INTRODUCTION}

Nonsteroidal anti-inflammatory drugs (NSAIDs) are among the most widely used drugs around the world. Internationally, many studies have reported important data relating to the adverse gastroduodenal reactions to NSAIDs, the main cause of morbidity and mortality associated with their use. ${ }^{1-3}$

The adverse gastrointestinal reactions associated with the use of NSAIDs represent about one fourth of all drug-

Pharmacy School, Federal University of Minas Gerais (UFMG) - Belo Horizonte/MG, Brazil.

Email: aribeiro@farmacia.ufmg.br

Received for publication on May 17, 2006.

Accepted for publication on June 19, 2006. related adverse reactions. They can be grouped as causing (i) symptoms (nausea, rash, dyspepsia, pain, anemia), (ii) gastric lesions, such as gastric or duodenal ulcers, or (iii) complications (hemorrhage or perforation of new ulcers or pre-existing ones). ${ }^{1}$ In Spain and Italy, about $38 \%$ of the hospital admissions due to bleeding caused by gastric or duodenal ulcer are related to the use of NSAIDs. ${ }^{2}$ In Finland, a study about the incidence of death related to the use of drugs in a university hospital, reported that gastrointestinal bleeding associated with the use of NSAIDs was the third most frequent fatal adverse reaction. ${ }^{3}$

Epidemiological studies show the variability of the factors that can alter the risk of gastrointestinal complication associated with the use of NSAIDs. This variability reflects methodological differences, such as the study design, the 
pathology definitions, the patients' ages, the dosage and the duration of NSAID use, among others. Most studies have shown that advanced age, a previous history of peptic ulcer, the simultaneous use of other NSAIDs, and the use of anticoagulants and corticosteroid are the most relevant factors related to the increase in the occurrence of peptic ulcer and complications. ${ }^{2,45}$ Likely risk factors also include infection by Helicobacter pylori and the ingestion of large quantities of alcohol.

In Brazil, important aspects related to NSAIDs are the fact of their being over-the-counter drugs and their presence in many drug combinations available in the pharmaceutical market. ${ }^{6}$ In the year 2000 , diclofenac potassium took first place in drug sales in the pharmaceutical industry. This marketing information is confirmed by studies on the use of the drug in the country, in which NSAIDs take one of the top places in the ranking of most used drugs by the population. ${ }^{7-10}$

In spite of the importance of NSAIDs to medical practice, the fact that they are the ones most frequently involved in adverse reactions, and the conclusions of many Brazilian studies regarding the indiscriminate and incorrect use of the NSAIDs under many circumstances, there are few specific studies about the social and medical implications of NSAIDs. In this context, the present study is presented. It represents the first consideration of the issue of NSAIDs use in a population undergoing upper endoscopy in a university hospital, in which the role of NSAIDs has been investigated in cases of occurrence of gastric lesions. This study investigated the association between exposure to NSAIDs and the occurrence of gastric lesions observed during the upper endoscopy.

\section{METHODS}

This study had a cross-sectional design and was carried out at Hospital das Clínicas of UFMG, a university hospital located in Belo Horizonte, Minas Gerais, Brazil, in the year 2000. This hospital primarily serves citizens who use the public health system. The project was approved by the Ethics Committee of the Hospital (ETIC 007/2000).

\section{Population Study}

The reference population included individuals who were 17 or over and had scheduled endoscopies. Patients unable to respond and patients undergoing specific endoscopy procedures (eg, sclerotherapy of esophageal varices, stenosis dilation of the esophagus, pyloric obstruction, or polypectomy) were excluded. A sample of 385 patients was required to obtain a $95 \%$ confidence interval of $+/-5 \%$ around a prevalence estimate of $50 \%$. Considering a loss of $15 \%$, a sampling size of 445 patients would have been large enough. However, the sample includes 582 patients who were chosen through systematic sampling.

\section{Data Collection}

The data collection was carried out between June and December 2000. The information was obtained through an interview made immediately before the upper endoscopy. A standardized questionnaire was used to collect information about the use of NSAIDs, socio-demographic characteristics, the use of alcohol and cigarettes, health problem history, and the use of other medicines. After the interview, the information about gastric lesions was collected from the upper endoscopy report.

\section{Study variables}

The outcome variables were the indicators of occurrence of gastric lesions described in the upper endoscopy report as follows: gastric erosions, gastric erosions with hematin pigment, and gastric ulcer (present/absent).

The use of NSAIDs during the 30 days preceding the upper endoscopy was considered, and all the covariates related to NSAIDs referred to this interval. Information was collected about any type of NSAID use-continuous or not, prescribed or not-over this 30-day period. The exposure to NSAIDs was categorized into 4 categories as follows: 1) regular use-the continuous use of NSAIDs anytime within the 30 days before the upper endoscopy and present at the time of the exam;2) interrupted regular use-continuous use of NSAIDs anytime within the 30 days before the exam but interrupted before the time of the exam; 3) sporadic use-sporadic use of NSAIDs anytime within the 30-day period before the time of the exam; 4) non-useno related use NSAIDs within the 30 days studied.

Concerning the duration of the therapy, 5 categories were defined for each type of use as follows: 1 = less than 7 days of NSAIDs use; $2=7$ through 15 days of use; $3=$ 16 through 30 days of use; $4=31$ days through 1 year of use; $5=$ more than 1 year of use.

The sociodemographic covariates studied were gender, age, education (in years of schooling), and individual monthly income calculated in terms of number of minimum salaries at the time of data collection).

The covariates related to lifestyle were the use of alcohol (do you consume any alcoholic beverage?) and the use of cigarettes (do you smoke any kind of cigarettes?).

The covariate related to the morbidity history included a previous history of peptic ulcer and/or digestive hemorrhage. 
Concerning the use of other medicines, the regular use of drugs prescribed or not in the last 30 days was investigated, especially that of corticosteroids and anticoagulants. Homeopathic products, and the preparation for which the composition was not identified even after some search in the local drugstores, were not considered.

\section{Statistical analysis}

All the covariates were categorical, and the univariate analysis was performed using Pearson chi-squared and Fisher exact tests. Multivariate logistic regression was used in the multivariate analysis. All the covariates with a $P$ value $<0.20$ in the univariate analysis were included in the multivariate logistic model. The covariates that were associated with NSAIDs use with a $P$ value $<0.05$ were retained in the model. The magnitude of association was measured using the odds-ratio (OR). The $95 \%$ confidence intervals were also reported. The data analysis was done using the software Stata, version 7.0.

\section{RESULTS}

From the 582 selected patients, 533 (91.6\%) were studied. Loss of 49 patients was due to failure in carrying out an upper endoscopy due to the patients' intolerance. There was however no difference in gender or age between patients who answered the questionnaire and those who did not.

The average age of the studied patients was 49 years. Most of them (45.8\%) had between 1 and 4 years of schooling, and $12.6 \%$ were illiterate. Twenty-eight percent of the patients (149) declared that they did not to have a monthly income. Of the 384 patients (72.0\%) who declared having an individual monthly income, most received between 1 and 3 minimum salaries (US $\$ 83.93$ to US $\$ 251.79$ ). Concerning lifestyles, only $18.5 \%$ of those interviewed declared themselves to be smokers, and $35.8 \%$ used alcoholic beverage.

The primary reasons for the endoscopy procedure were as follows: gastrointestinal symptoms, 310 patients
(58.2\%); treatment of digestive pathologies, 97 patients (18.2\%); and preoperative procedures, 28 patients (5.3\%). One hundred and two patients $(19.1 \%)$ reported a previous history of peptic ulcer and/or digestive hemorrhage. Most patients also reported having some kind of disease $(80.7 \%)$, especially cardiovascular diseases $(22.8 \%)$ and diseases of the skeletal-muscular system (18.3\%). Concerning the use of non-NSAIDs, 91 patients (17.0\%) used 4 or more drugs on a regular basis. Only 16 patients used corticosteroids, and only 5 patients used anticoagulants.

Among those interviewed, 274 patients (51.4\%) regularly used at least 1 kind of non-NSAID. From the 533 studied patients, $182(34.1 \%)$ declared the use of some kind of NSAID during some period within the 30 days before the interview, adding up to a total of 249 used drugs. Among them, most $(70.9 \%)$ used only one NSAID in the studied period. However, $6.6 \%$ of the users mentioned the use of 3 or more nonsteroidal anti-inflammatory drugs in the period considered.

Regarding the duration of use, the highest percentage observed was for the sporadic use and the use for a period of less than 7 days (51.4\%). On the other hand, among the patients who reported regular use of NSAIDs, $70.7 \%$ used some NSAID for a period greater than 15 days. The most used drug was the acetylsalicylic acid (59.5\%), followed by the diclofenac $(28.1 \%)$, and the piroxicam $(2.8 \%)$.

According to the upper endoscopy report, 461 patients $(86.5 \%)$ presented some kind of alteration in the gastrointestinal tract. Of the total number of interviewed people, 195 (36.6\%) presented gastric erosions; 29 (5.4\%) presented gastric erosions with hematinic pigment, and 21 $(4.0 \%)$ received a diagnosis of gastric ulcer, which was later confirmed by histological examination.

Table 1 shows the distribution of the NSAIDs-using patients according to the occurrence of the gastric erosions, gastric erosions with hematin pigment, and gastric ulcer. The table shows the estimated value and the $95 \%$ confidence interval of the odds ratio (OR) for the occurrence of each of these lesions.

As shown on Table 1, a strong and significant association between the use of NSAIDs and the occurrence of gas-

Table 1 - Association between nonsteroidal anti-inflammatory drugs (NSAID)use and the occurrence of gastric lesions according to univariate analysis

\begin{tabular}{|c|c|c|c|c|c|c|c|c|c|}
\hline \multirow[t]{2}{*}{ NSAID use } & \multicolumn{2}{|c|}{ Gastric erosions } & \multirow[t]{2}{*}{$\begin{array}{c}\text { Odds Ratio } \\
95 \% \text { CI }\end{array}$} & \multicolumn{2}{|c|}{$\begin{array}{l}\text { Gastric erosions } \\
\text { with hematin }\end{array}$} & \multirow[t]{2}{*}{$\begin{array}{c}\text { Odds Ratio } \\
95 \% \mathrm{CI}\end{array}$} & \multicolumn{2}{|c|}{ Gastric ulcer } & \multirow[t]{2}{*}{$\begin{array}{c}\text { Odds Ratio } \\
95 \% \mathrm{CI}\end{array}$} \\
\hline & Absent & Present & & Absent & Present & & Absent & Present & \\
\hline No & $245(72.5 \%)$ & $106(54.4 \%)$ & 1.0 & $339(67.3 \%)$ & $12(41.4 \%)$ & 1.0 & $341(66.6 \%)$ & $10(47.6 \%)$ & 1.0 \\
\hline Yes & $93(27.5 \%)$ & $89(45.6 \%)$ & $\begin{array}{c}2.21 \\
1.50-3.27\end{array}$ & $165(32.7 \%)$ & $17(58.6 \%)$ & $\begin{array}{c}2.91 \\
1.27-6.71\end{array}$ & $171(33.4 \%)$ & $11(52.4 \%)$ & $\begin{array}{c}2.17 \\
0.83-5.70\end{array}$ \\
\hline
\end{tabular}


tric lesions and gastric lesions with hematin was observed. Concerning the occurrence of gastric ulcer, an association was possibly present, but not statistically significant.

Considering the subsample of regular NSAIDs users, a comparison was made between the occurrence of lesions in patients who used NSAIDs for more than 15 days and in those who used them for a shorter period. Table 2 shows the results of this comparison. A positive and statistically significant association between the use of NSAIDs for more than 15 days and the occurrence of gastric lesions was observed.

A model including the use of NSAIDs and the other relevant covariates was estimated for each outcome variable. Table 3 presents the estimated adjusted odds ratio with the 95\% confidence interval for the association between NSAIDs use and the occurrence of each studied gastric lesion. The use of NSAIDs was modeled separately for each outcome variable. Age, years of schooling, individual monthly income, use of alcoholic beverages, previous history of ulcer and/or digestive hemorrhage, and the regular use of other medicines were important confounding fac- tors for the association between the use of NSAIDs and the occurrence of gastric lesions. For the association between the use of NSAIDs and gastric lesions with hematin, only age and years of schooling were important confounding factors. In the case of association between the use of NSAIDs and gastric ulcer, there was an adjustment based on the age and on the previous history of ulcer and/or digestive hemorrhage. As it can be seen on Table 3, the use of NSAIDs was strongly and independently associated with the occurrence of each of the studied lesions.

Table 4 presents the estimated odds ratio and the $95 \%$ confidence interval for the association between the use of NSAIDs for more than 15 days and the occurrence of the gastric lesions. Additionally, Table 4 shows that the period of NSAIDs use was modeled separately for each lesion of interest. For each association, the confounding factors did not appreciably alter the findings of the univariate analysis. Therefore, for each considered lesion, the use of NSAIDs for more than 15 days was strongly and independently associated with their occurrence.

Table 2 - Association between nonsteroidal anti-inflammatory drugs (NSAID) use for more than 15 days and the occurrence of gastric lesions according to univariate analysis

\begin{tabular}{|c|c|c|c|c|c|c|c|c|c|}
\hline \multirow[t]{2}{*}{$\begin{array}{l}\text { NSAID use } \\
\text { use }>15 \text { days }\end{array}$} & \multicolumn{2}{|c|}{ Gastric erosions } & \multirow[t]{2}{*}{$\begin{array}{c}\text { Odds Ratio } \\
95 \% \text { CI }\end{array}$} & \multicolumn{2}{|c|}{$\begin{array}{l}\text { Gastric erosions } \\
\text { with hematin }\end{array}$} & \multirow[t]{2}{*}{$\begin{array}{c}\text { Odds Ratio } \\
95 \% \text { CI }\end{array}$} & \multicolumn{2}{|c|}{ Gastric ulcer } & \multirow[t]{2}{*}{$\begin{array}{c}\text { Odds Ratio } \\
95 \% \text { CI }\end{array}$} \\
\hline & Absent & Present & & Absent & Present & & Absent & Present & \\
\hline $\mathrm{No}^{*}$ & $324(95.9 \%)$ & $144(73.8 \%)$ & 1.0 & $450(89.3 \%)$ & $18(62.1 \%)$ & 1.0 & $456(89.1 \%)$ & $12(57.1 \%)$ & 1.0 \\
\hline Yes & $14(4.1 \%)$ & $51(26.2 \%)$ & $\begin{array}{c}8.20 \\
4.24-16.07\end{array}$ & $54(10.7 \%)$ & $11(37.9 \%)$ & $\begin{array}{c}5.09 \\
2.12-12.11\end{array}$ & $56(10.9 \%)$ & $9(42.9 \%)$ & $\begin{array}{c}6.11 \\
2.25-16.41\end{array}$ \\
\hline
\end{tabular}

* includes 15-day or less NSAID users and NSAID non-users.

Table 3 - Results of multivariate analysis of association between nonsteroidal anti-inflammatory drugs use and the occurrence of gastric lesions

\begin{tabular}{|c|c|c|c|c|c|c|}
\hline & \multicolumn{2}{|c|}{ Gastric erosions ${ }^{\mathrm{a}}$} & \multicolumn{2}{|c|}{ Gastric erosions with hematin ${ }^{\mathrm{b}}$} & \multicolumn{2}{|c|}{ Gastric ulcer ${ }^{\mathrm{c}}$} \\
\hline & $\begin{array}{c}\text { Unadjusted Odds } \\
\text { Ratio 95\% CI }\end{array}$ & $\begin{array}{c}\text { Adjusted Odds } \\
\text { Ratio95\% CI }\end{array}$ & $\begin{array}{l}\text { Unadjusted Odds } \\
\text { Ratio95\% CI }\end{array}$ & $\begin{array}{c}\text { Adjusted Odds } \\
\text { Ratio95\% CI }\end{array}$ & $\begin{array}{c}\text { Unadjusted Odds } \\
\text { Ratio95\% CI }\end{array}$ & $\begin{array}{c}\text { Adjusted Odds } \\
\text { Ratio95\% CI }\end{array}$ \\
\hline NSAID use & $\begin{array}{c}2.21 \\
1.50-3.27\end{array}$ & $\begin{array}{c}1.98 \\
1.28-3.05\end{array}$ & $\begin{array}{c}2.91 \\
1.27-6.71\end{array}$ & $\begin{array}{c}2.82 \\
1.29-6.14\end{array}$ & $\begin{array}{c}2.17 \\
0.83-5.70\end{array}$ & $\begin{array}{c}2.96 \\
1.08-8.07\end{array}$ \\
\hline
\end{tabular}

${ }^{a}$ controlled for age, education (years of schooling), individual monthly income, alcohol use, previous history of ulcer or/and digestive bleeding and regular use of another drugs. ${ }^{b}$ controlled for age and education (years of schooling). ${ }^{c}$ controlled for age and previous history of ulcer or/and digestive bleeding.

Table 4 - Results of multivariate analysis of association between nonsteroidal anti-inflammatory drugs (NSAID) use for more than 15 days and the occurrence of gastric lesions

\begin{tabular}{|c|c|c|c|c|c|c|}
\hline & \multicolumn{2}{|c|}{ Gastric erosions ${ }^{\mathrm{a}}$} & \multicolumn{2}{|c|}{ Gastric erosions with hematin ${ }^{\mathrm{b}}$} & \multicolumn{2}{|c|}{ Gastric ulcer $^{c}$} \\
\hline & Unadjusted Odds & Adjusted Odds & Unadjusted Odds & Adjusted Odds & Unadjusted Odds & Adjusted Odds \\
\hline & Ratio $95 \%$ CI & Ratio95\% CI & Ratio95\% CI & Ratio95\% CI & Ratio95\% CI & Ratio95\% CI \\
\hline \multirow[t]{2}{*}{ NSAID use $>15$ days } & 8.20 & 7.76 & 5.09 & 5.03 & 6.11 & 6.59 \\
\hline & 4.24-16.07 & $3.65-16.54$ & $2.12-12.11$ & $2.03-12.47$ & $2.25-16.41$ & $2.11-20.51$ \\
\hline
\end{tabular}

${ }^{a}$ controlled for age, education of schooling), individual monthly income, alcohol use, previous history of ulcer or/and digestive bleeding and regular use of another drugs. ${ }^{\mathrm{b}}$ controlled for age and education (years of schooling). ${ }^{\mathrm{c}}$ controlled for age and previous history of ulcer or/and digestive bleeding. 


\section{DISCUSSION}

In Brazil, pharmacoepidemiology is still a new research field, and the extent of the occurrence of gastrointestinal injuries among NSAID users is poorly understood. It is likely that this is the first study that addresses this subject, and it will certainly support the identification of different intervention areas. A few reports have discussed this problem under other circunstances ${ }^{11,12}$

The prevalence of the NSAIDs use in the sample was $34.0 \%$ in the investigated period. Concerning the methodological differences, a study of the use of minor analgesics and NSAIDs by people over 18 in Sweden found a prevalence of $35.0 \% .{ }^{13}$ Because NSAIDs are nonprescription drugs in Brazil, are commonly used symptomatically, and are present in a great variety of medicine combinations, a higher prevalence would be expected. On the other hand, it is important to note the specificity of this sample, which consisted of patients undergoing upper endoscopy and who could have been warned about the risks associated with the use of NSAIDs, during treatment of previous gastrointestinal problems.

A discussion about the most used NSAIDs by the population is necessary. The study findings fit well with many other studies that have found acetylsalicylic acid and diclofenac as the most used NSAIDs. ${ }^{8,14}$ A relevant finding is that the 3 most used NSAIDs, which are acetylsalicylic acid, diclofenac, and piroxicam, are among the ones that have an intermediate-to-high level of gastrointestinal sideeffect risk..$^{15-18}$ Excluding acetylsalicylic acid, which can be used as a platelet anti-aggregator, diclofenac as well as the piroxicam can be replaced by safer and more efficient alternative drugs.

The prevalence of gastroduodenal lesions associated with the use of the NSAIDs depends on the target population. Studies show that about $40.0 \%$ of the individuals who use one kind of NSAID can present gastric erosion. ${ }^{19}$ According to other studies, this prevalence can reach $100 \%$, mainly in the first month of treatment. ${ }^{20}$ In the present study, among the individuals who mentioned some use of NSAIDs in the investigated period, the prevalence of gastric erosions reached $49 \%$. Considering only the patients who used NSAIDs for more than 30 days (58 individuals), $81 \%$ presented gastric erosions.

The results of the multivariate analysis show that even after the control of covariates, the association between the use of NSAID and the presence of gastric erosions was still significant, with an odds ratio equal to 1.98 (95.0\% IC 1.283.05). Although some authors do not consider the erosions to be precursors to gastrointestinal complications since they hardly ever develop into ulcers, ${ }^{21,22}$ other studies show a higher risk of gastric ulcers in patients whose diagnosis con- firmed gastric erosions and a chronicle use of NSAIDs, independent of the prophylactic treatment. ${ }^{23,24}$ These findings were confirmed by another study that also suggested that the presence of erosions is a better predictor of ulceration risk than the number of gastric erosions..$^{25}$

In spite of the methodological differences between the present study and the other ones cited, the prevalence of $81.0 \%$ of gastric erosions in long-term NSAID users suggests the necessity for strict attention, so that gastrointestinal complications such as digestive hemorrhage or gastric ulcer can be prevented. It must be added that although digestive hemorrhages more frequently develop from ulcers, they can also develop from gastric erosions, ${ }^{15,26}$ emphasizing the significance of the prevalence of gastric erosion found in this study.

Another controversial point is the association between the longer period of NSAID use and the presence of gastric erosions. Most authors assert that the gastric erosions heal as time goes by and that the chronic use of NSAIDs is accompanied by adaptation by the gastric mucous to mitigate the harm caused by these drugs. The results of this study support those of others that assert the variability in the adaptation phenomenon of gastric mucous, since it does not occur in all patients. This study also supports other studies that have evaluated endoscopic lesions in patients undergoing long treatments with NSAIDs, for instance, for a period more than 6 months, who presented a considerable frequency of gastric lesions. ${ }^{25,27}$

Concerning the gastric erosions with hematin pigment, no detailed literature was found, since most studies encounter them in the same context as for gastric erosions. The occurrence of this lesion and its strong association with the NSAID use is of concern, since these pigments generally indicate severe harm to the mucosa that is highly associated with the topical aggression caused by the use of NSAIDs. ${ }^{21}$ The results here presented confirm this association through the odds ratio, which equals 2.82 (95.0\% IC 1.29-6.14) after the control of covariates.

The prevalence of duodenal and/or gastric ulcers in patients using NSAIDs for more than 1 month has been reported to be $5.0 \%$ to $30.0 \% .{ }^{20}$ In cross-sectional studies, this prevalence has been reported to be $14.0 \%$ to $31.0 \% .^{22}$ In a cross-sectional study of the impact of NSAID use on the prevalence of peptic ulcer carried out in Finland, 16.0\% of the individuals who used NSAIDs regularly presented this kind of pathology. ${ }^{28}$ In the present study the patients who regularly used NSAIDs $(\mathrm{n}=58)$ presented a prevalence of gastric ulcer of $32.7 \%$.

This study showed an association between the regular use of NSAIDs and the presence of gastric ulcers with an odds ratio equal to 2.96 (95.0\% IC 1.08-8.07). Most re- 
searchers describe the relative risk of gastric ulcer in NSAID users of about 3.0 or more. ${ }^{16,28}$ Regarding a time of use greater than 30 days, the association was demonstrated by an odds ratio equal to 7.11 (95.0\% IC 2.28-22.13) in the present study. Although this result shows that the more an individual uses NSAIDs, the higher the chance of gastric ulcer, which is in agreement with other investigations, this odds ratio must be interpreted cautiously. The confidence interval is wide, probably due to the low prevalence of gastric ulcer and the risk factor, ie, the use of NSAIDs for a period greater than 1 month $(4.0 \%$ and $10.9 \%$, respectively).

Although the focus of this study was on the association between the use of NSAIDs and the presence of gastric lesions, it is important to note the behavior of some of the covariates. Age was an important confounding factor for the association of NSAIDs use and the occurrence of gastric erosions and gastric ulcers, but gender was not a confounding factor. Although income has not been mentioned in the literature as a confounding factor for the association of the NSAID use and the occurrence of gastric lesions, income was found to be a confounding factor in the present study. Individuals whose income was equal to or higher than 3 minimum salaries were more likely to use NSAIDs as well as to have gastric erosions.

Previous history of ulcers and/or digestive hemorrhage, known as a confounding factor in the association between the use of NSAID and gastric erosions and gastric ulcers, showed a significant independent association with these lesions. It is important to emphasize that among the patients with a previous history of peptic ulcer/digestive hemorrhage, the use of NSAIDs was significantly less than among those without such a history, which would be expected.

The use of alcohol has also been considered important as a confounding factor for the association between the use of NSAID and gastric erosions. However, for the gastric ulcer, this association was not statistically significant. Smoking was also shown not to be a confounding factor. Since this was an exploratory study, the use of alcohol and cigarettes was not quantified, although the quantity used could affect the occurrence of gastric erosions. Consequently, lack of quantitation could also have influenced the research results.

The regular use of other drugs was a confounding factor for the association of NSAID use and the gastric erosions. A possible explanation for this behavior is, on one hand, that the NSAIDs are found in many situations of polypharmacy. ${ }^{29,30}$ On the other hand, a higher number of drugs may mean a higher level of population morbidity or even the existence of concomitant chronic diseases that in some circumstances increase the individual's risk for gastrointestinal problems. ${ }^{31-33}$ The importance of the concomitant use of corticosteroids and anticoagulants with NSAIDs and the potential increase in the risk of gastrointestinal lesions and the complications of these lesions is emphasized in the literature. ${ }^{31-33}$ This relationship could not be investigated in this study, because the use of these drugs occurred infrequently (16 and 5 patients, respectively), which limited the power of the study to analyze these covariates. In general, these findings point to a necessity of a national and wider study, evaluating the interrelations among these factors and the use of NSAIDs, as well as the occurrence of gastric lesions.

Another limitation in this study is the fact that the association between infection by Helicobacter pylori and the studied lesions as a possible interfering factor in the association between the use of NSAID and the mentioned lesions was not studied, since not all the patients underwent tests to detect the infection. Since the test was not randomly assigned, it is possible that there were some differences between the group undergoing the test and the group that did not. Further study is necessary to better comprehend this relationship.

Considering methodological aspects, the procedures were standardized to avoid bias. The internal validity of the study is ensured by the small sample loss. From the epidemiological point of view, the main limitation of the study is the fact that the results are not strong enough to make an inference about the general population. On the other hand, the study's findings follow some tendencies described in literature as previously presented.

The study showed that, after controlling for age, individual monthly income, schooling, use of alcohol, smoking, previous history of ulcers and/or digestive hemorrhage, and regular use of other drugs, the use of NSAIDs is an independent factor associated with the occurrence of gastric erosions and gastric ulcers. In spite of the limitations of the transversal design, it is possible that the duration of drug use was one of the most important risk factors.

It is important to emphasize that the findings of this study are from a setting of a university hospital, an excellence center in Brazil, which almost guarantees that the interviewed patients had already used other services in the same hospital and probably had received safer and better prescriptions and drug-use orientation than the population that goes to other health institutions in the country.

Based on the results found, a concern about the use of NSAIDs remains, as well as its consequences with respect to other Brazilian scenarios. It is reasonable to accept that a considerable percentage of the gastric lesions found could have been avoided, provided that preventive measures to stimulate the rational use of the drugs had been taken. 
Ribeiro AQ, Sevalho G, César C. Uso de antiinflamatórios não-esteróides e ocorrência de lesões gástricas entre pacientes submetidos à endoscopia digestiva alta em Hospital Universitário no Brasil. CLINICS. 2006;61(5): 409-16.

INTRODUÇÃO: No Brasil são bastante evidentes os riscos associados ao uso de medicamentos. No entanto, tal questão não é devidamente privilegiada no campo da investigação científica. $\mathrm{O}$ presente estudo se refere ao uso de antiinflamatórios não-esteróides, fármacos amplamente utilizados no país. O objetivo foi investigar o uso de antiinflamatórios não-esteróides entre pacientes submetidos à endoscopia digestiva alta no Hospital das Clínicas da Universidade Federal de Minas Gerais e sua associação com a ocorrência de erosões gástricas, erosões gástricas com pigmento de hematina e úlcera gástrica.

MÉTODOS: Estudo transversal em que 533 pacientes com idade igual ou superior a 17 anos foram entrevistados no período de junho a dezembro de 2000. Os dados foram submetidos às análises bivariada e multivariada.
RESULTADOS: Mais de dois terços da população entrevistada relatou o uso de antiinflamatórios não-esteróides no período de um mês anterior à endoscopia digestiva alta. Os antiinflamatórios mais utilizados foram o ácido acetilsalicílico e o diclofenaco. Evidenciou-se uma associação positiva e significativa entre o uso desses fármacos e a ocorrência das lesões em questão. Ao se avaliar a associação entre o uso de antiinflamatórios não-esteróides por um período superior a 15 dias e a ocorrência das lesões gástricas, esta foi positiva e significativa, apresentado odds ratio superiores àqueles apresentados para as associações anteriores.

CONCLUSÕES: Os resultados sugerem que os antiinflamatórios não-esteróides têm uma associação significativa com a ocorrência de lesões gástricas e apontam para a necessidade de aprofundamento no estudo desta questão no Brasil.

UNITERMOS: Farmacoepidemiologia. Antiinflamatórios não-esteróides. Endoscopia digestiva alta. Reações adversas a medicamentos.

\section{REFERENCES}

1. Barrier $\mathrm{CH}$, Hirschowitz BI. Controversies in the detection and management of nonsteroidal antiinflammatory drug-induced side effects of the upper gastrointestinal tract. Arthritis and Rheum. 1989;327:92632.

2. Laporte JR, Ibanez L, Vidal X, Vendrell L, Leone R. Upper gastrointestinal bleeding associated with the use of NSAIDs: newer versus older agents. Drug Saf. 2004;276:411-20.

3. Juntti-Patinen L, Neuvonen PJ. Drug-related deaths in a university central hospital. Eur J Clin Pharmacol. 2002;58:479-82.

4. Scarpignato C, Bjarnason I, Bretagne JF, De Pouvourville G, Garcia Rodriguez LA, et al. Towards a safer gastrointestinal antiinflammatory therapy. Gastroenterol Int. 1999;12:186-215.

5. Peura, DA. Prevention of nonsteroidal anti-inflammatory drugassociated gastrointestinal symptoms and ulcer complications. Am J Med. 2004;117 (Suppl. 5A):63S-71S.

6. BiancarelliI A, Lambert P. Benefício de genérico pode demorar 2 anos. Folha São Paulo, São Paulo, 20 fev. 2000.

7. Béria JU, Victora CG, Barros FC, Teixeira AB, Lombardi C. Epidemiologia do consumo de medicamentos em crianças no centro urbano da região sul do Brasil. Rev Saúde Publica 1993;27:95-104.

8. Pepe VLE. Estudo sobre a prescrição de medicamentos em uma Unidade de Atenção Primária. 1994. 210 p. Dissertação (Mestrado em Saúde Coletiva) - Instituto de Medicina Social, Universidade Estadual do Rio de Janeiro, Rio de Janeiro.
9. Vilarino JF, Soares IC, Silveira CM, Rodel AP, Bortoli R, Lemos RR. Perfil da automedicação em município do sul do Brasil. Rev Saúde Publica 1998;32:43-49.

10. Mosegui GBG, Rozenfeld S, Veras RP, Vianna CMM. Avaliação da qualidade do uso de medicamentos em idosos. Rev Saude Publica 1999;33:437-44.

11. Dainesi, SM. Pharmacovigilance: More than ever, an overall responsibility. Clinics. 2005; 60:267-270.

12. Anacleto TA, Perini E, Rosa MB, César CC. Medication errors and drugdispensing systems in the hospital pharmacy. Clinics. 2005; 60(4):257325-332

13. Antonov K, Isacson D. Use of analgesics in Sweden-the importance of sociodemographic factors, physical fitness, health and health-related factors, and working conditions. Soc Sci Med. 1996;42:1473-81.

14. Hogan DB, Campbell NRC, Crutcher R, MacLeoad N. Prescription of nonsteroidal anti-inflammatory drugs for elderly people in Alberta. Can Med Assoc J. 1994;151:315-22.

15. Laporte JR, Carné X, Vidal X, Moreno V, Juan J. Upper gastrointestinal bleeding in relation to previous use of analgesics and non-steroidal antiinflammatory drugs. Lancet. 1991;337:85-9.

16. Garcia Rodriguez LA, Jick H. Risk of upper gastrointestinal bleeding and perforation associated with individual non-steroidal antiinflammatory drugs. Lancet. 1994;343:769-72. 
17. Henry D, Dobson A, Turner C. Variability in the risk of major .gastrointestinal complications from nonaspirin nonsteroidal antiinflammatory drugs. Gastroenterology. 1993;105:1078-88.

18. Hernández-Diaz S, Garcia-Rodriguez LA. Epidemiologic assessment of the safety of conventional nonsteroidal anti-inflammatory drugs. Excerpta Med. 2001;110 (Suppl.3A):20S-27S.

19. Úlcera gastroduodenal por antiinflamatorios no esteroides y su prevención. Butll groc. 1997;10:9-11.

20. Raskin JB. Gastrointestinal effects of nonsteroidal antiinflammatory therapy. Am J Med. 1999;106 (Suppl. 5B):3S-12S.

21. Cooper GS, Blades EW. Indications, contraindications and complications of upper gastrointestinal endoscopy. In Gastroenterologic endoscopy 2. ed. Sivak, MVJ, editor. Baltimore, Maryland: W.B. Saunders; 1999; CD-ROM. Produced by Corporate Technology Ventures.

22. Zaterka S. Lesões induzidas por AINE no sistema digestório. Rev Bras Med. 2000;57:882-900

23. Agrawal NM, Roth S, Graham DY, White RH. Misoprostol compared with sucralfate in the prevention of nonsteroidal anti-inflammatory druginduced gastric ulcer. A randomized, controlled trial. Ann Intern Med. 1991;115:195-200.

24. Hawkey CJ, Naesdal J, Wilson I, Langstrom G, Swannel AJ, Peacock RA, Yeomans ND. Relative contribution of mucosal injury and Helicobacter pylori in the development of gastroduodenal lesions in patients taking non-steroidal anti-inflammatory drugs. Gut. 2002;51:336-43.
25. Taha AS, Sturrock RD, Russel RI. Mucosal erosions in longterm nonsteroidal anti-inflammatory drug users: predisposition to ulceration and relation to Helicobacter pylori. Gut. 1995;36:334-6.

26. Longstreth GF. Epidemiology of hospitalization for acute upper gastrointestinal hemorrhage: a population-based study. Am J Gastroenterol. 1995;90:206-10.

27. Cheatun DE, Arvanitakis C, Gumpel M, Stead H, Geis GS. An .endoscopic study of gastroduodenal lesions induced by nonsteroidal anti- inflammatory drugs. Clin Ther. 1999;21:992-1003.

28. Voutilainen M, Mäntynen T, Färkkilä MJ, Sipponen P. Impact of nonsteroidal anti-inflammatory drug and aspirin use on the prevalence of dyspepsia and uncomplicated peptic ulcer disease. Scand J Gastroenterol. 2001;36:817-21.

29. Klaukka T, Makela M, Sipila J., Martikainen J. Multiuse of medicines in Finland. Med Care. 1993;31:445-50.

30. Bjerrum L, Andersen M, Petersen G, Kragstrup J. Exposure to potential drug interactions in primary health care. Scand J Prim Health Care. 2003;21:153-8

31. Piper JM, Ray WA, Daugherty JR, Griffin MR. Corticosteroid use and peptic ulcer disease: role of nonsteroidal anti-inflammatory drugs. Ann Intern Med. 1991;114:735-40.

32. Peura, DA. Prevention of nonsteroidal anti-inflammatory drugassociated gastrointestinal symptoms and ulcer complications. Am J Med. 2004;117 (Suppl. 5A):63S-71S.

33. Russel RI. Defining patients at risk of non-seteroidal anti-inflammatory drug gastropathy. Ital J Gastroenterol Hepatol. 1999;31 (Suppl 1):S14S18. 